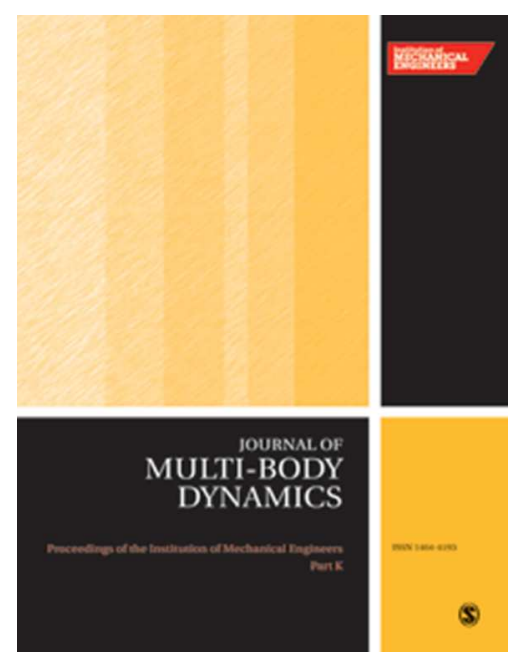

\title{
Simulation of rail wheel axle bearing vibration due to local damages on outer races
}

\begin{tabular}{|r|l|}
\hline Journal: & $\begin{array}{l}\text { Proceedings of the Institution of Mechanical Engineers, Part K: Journal of } \\
\text { Multibody Dynamics }\end{array}$ \\
\hline Manuscript ID & JMBD-18-0023.R2 \\
\hline Danuscript Type: & Original Article \\
\hline Complete List of Authors: & $\begin{array}{r}\text { Liu, Hongbin; Henan University of Science and Technology, School of } \\
\text { Mechanical and Electrical Engineering } \\
\text { Wang, Ling; University of Southampton, Faculty of Engineering and the } \\
\text { Environment } \\
\text { Li, Yunbin; Henan University of Science and Technology, School of } \\
\text { Mechanical and Electrical Engineering }\end{array}$ \\
\hline Keywords: & $\begin{array}{l}\text { cylinder roller bearing, fundamental frequencies, damage, nonlinear } \\
\text { vibration, dynamic analysis }\end{array}$ \\
\hline & $\begin{array}{l}\text { This paper presents a dynamic model of bearings that simulates the } \\
\text { vibration of rail wheel bearings due to local damages such as pits on the } \\
\text { bearing outer race. The model, based on the multi-body simulation } \\
\text { software Recurdyn, integrates the major parts of the functionalities } \\
\text { according to the three-dimensional model and railway axle dynamic } \\
\text { system. Three types of surface damages on the raceway of cylindrical roller } \\
\text { bearings were designed and evaluated by the dynamic model developed in } \\
\text { this study. The results show that the dynamic model can effectively } \\
\text { simulate the influence of the damages on the bearing vibration under } \\
\text { varied pit shape and size. Furthermore, the model can predict the level of } \\
\text { bearing damage based on the peak value of bearing vibration in frequency } \\
\text { domain. }\end{array}$ \\
\hline Abstractions
\end{tabular}




\title{
Simulation of rail wheel axle bearing vibration due to local damages on outer races
}

\author{
Hongbin Liu ${ }^{\mathrm{a}}$, Ling Wang ${ }^{\mathrm{b}}$, Yunbin $\mathrm{Li}^{\mathrm{a}}$ \\ ${ }^{a}$ School of Mechatronics Engineering, Henan University of Science and Technology, Luoyang, China \\ ${ }^{\mathrm{b}}$ national Centre for Advanced Tribology at Southampton (nCATS), Faculty of Engineering and the Environment, University of \\ Southampton, Southampton, UK
}

\begin{abstract}
This paper presents a dynamic model of bearings that simulates the vibration of rail wheel bearings due to local damages such as pits on the bearing outer race. The model, based on the multi-body simulation software Recurdyn, integrates the major parts of the functionalities according to the three-dimensional model and railway axle dynamic system. Three types of surface damages on the raceway of cylindrical roller bearings were designed and evaluated by the dynamic model developed in this study. The results show that the dynamic model can effectively simulate the influence of the damages on the bearing vibration under varied pit shape and size. Furthermore, the model can predict the level of bearing damage based on the peak value of bearing vibration in frequency domain.
\end{abstract}

Keywords: cylinder roller bearing; nonlinear vibration; dynamic analysis; damage; fundamental frequencies.

\begin{tabular}{|c|c|c|c|}
\hline \multicolumn{4}{|c|}{ Nomenclatures } \\
\hline B & width of bearing (mm) & $1 / M$ & Poisson ratio \\
\hline BPF & roller pass frequency $(\mathrm{Hz})$ & $\mathrm{N}$ & number of rollers \\
\hline BPFI & ball pass frequency inner race $(\mathrm{Hz})$ & $\mathrm{P}$ & pitch diameter $(\mathrm{mm})$ \\
\hline BPFO & ball pass frequency outer race $(\mathrm{Hz})$ & $r_{\theta i}$ & The radial displacement \\
\hline $\mathrm{c}$ & equivalent viscous damping (Ns/m) & $\mathrm{t}$ & time $(s)$ \\
\hline $\mathrm{d}$ & depth of damage pits (mm) & $v_{d}$ & dynamic threshold velocity (m/s) \\
\hline $\mathrm{dn}$ & inner diameter of bearing $(\mathrm{mm})$ & $v_{s}$ & static threshold velocity $(\mathrm{m} / \mathrm{s})$ \\
\hline Dw & diameter of rollers $(\mathrm{mm})$ & w & width of damage pits (mm) \\
\hline Dy & outer diameter of bearing $(\mathrm{mm})$ & $\gamma$ & internal radial clearance of bearing (um) \\
\hline E & elastic modulus $\left(\mathrm{N} / \mathrm{m}^{2}\right)$ & $\delta$ & Penetration (mm) \\
\hline$f$ & vibration frequency $(\mathrm{Hz})$ & $\dot{\delta}$ & time differentiation of the penetration \\
\hline$f_{n}$ & contact normal force $(\mathrm{N})$ & $\theta$ & contact angle \\
\hline $\mathrm{F}$ & shaft frequency $(\mathrm{Hz})$ & $\theta_{\mathrm{i}}$ & angular location of damage pit \\
\hline FTF & fundamental train frequency $(\mathrm{Hz})$ & $\lambda$ & Hertz coefficients \\
\hline$k$ & Spring coefficient $(\mathrm{N} / \mathrm{m})$ & $\Lambda$ & Hertz coefficients \\
\hline$K$ & Hertz coefficients & $\mu$ & friction coefficient \\
\hline $\mathrm{K}_{\mathrm{B}}$ & bearing stiffness matrix & $\mu_{d}$ & dynamic threshold coefficient of friction \\
\hline Lw & length of rollers $(\mathrm{mm})$ & $\mu_{s}$ & static threshold coefficient of friction \\
\hline$m_{1, m_{2}}$ & $\begin{array}{l}\text { Exponents generate a non-linear contact } \\
\text { force }\end{array}$ & $\sum \rho$ & the sum of curvature $(1 / \mathrm{mm})$ \\
\hline $\mathrm{m} 3$ & $\begin{array}{l}\text { exponent yields an indentation damping } \\
\text { effect }\end{array}$ & $\psi$ & loss factor \\
\hline
\end{tabular}

\section{Introduction}

Train wheel axle bearings are among the components of rail vehicles subjected to the highest loads, and play a critical role in the safety of railroad operation [1]. In the course of bearing operation, there are many mechanisms of bearing failure. The most likely ones are wear which is as a result of depletion of a film of lubricant between the rolling elements and raceways [2]. And the other is as the result of sub-surface stresses causing inelastic defomation of surfaces (excess stresses/fatigue spalling) in the presence of flaws such as pores and cavities beneath the contacting surfaces [3-5]. Initially the damage may only be mild wear on the surface due to fatigue, which 
subsequently grow to fracture and cracking damages on the bearing [6]. Serious damages on rail axle bearings can lead to disastrous derailments causing human casualties [7]. As one of the most important transportation systems, train health monitoring and prediction of wheel axle bearings condition is becoming more and more crucial for the safety and reliability of the rail-train systems especially for the high-speed trains $[8,9]$. Significant amount of effort has been made by the rail industry to improve train maintenance using online condition monitoring techniques such as vibration monitoring to reduce unexpected train failures [10,11]. Fatigue spalling causes pitting, which can be represented as local damage on raceway surfaces, These damages/pits, etc induce bearing vibration which have been studied by many authors, creating flaws on the rolling surfaces and monitor the vibrations[12,13].

Condition monitoring as a mature technology, offers capabilities to increase safety and reliability as well as extends train maintenance intervals. At present, research on condition monitoring of rail wheel bearings, mainly include speed, temperature, acoustic and vibration monitoring $[14,15]$. There are many other sources of vibration from bearings, which may be incorrectly construed as a single event localised effect, such as the presence of offsized rolling elements. Off-sized rolling element causes a vibration frequency twice the element rolling speed [16], and a pit on the outer race provides an impulse at ball-to-outer relative speed, sometimes called ball-pass frequency[17]. Whenever, a local damage on a bearing element interacts with its mating surface, abrupt changes in the contact stresses at the interface are expected, generating a pulse of very short duration. This pulse produces vibration which can be monitored to detect the presence of a damage in the bearing [18,19]. In the frequency domain analysis of the bearing vibration, bearing damage frequencies are generated by the impact of the rolling elements on damage pits (very small piece of material removed) on the outer, inner ring or cage; a pit on a rolling element can also generate a specific frequency [20,21]. Bearing symptoms matching up with fundamental train frequencies (FTFs) in this case, confirms bearing damages of certain elements. So condition monitoring based on the analysis of vibration signals has shown a great success based on the characterization of bearing system conditions allowing early detection of bearing damages [22,23].

In recent years condition monitoring of train axle bearings has become a hot research topic around the world due to the high demands [24-26]. However early and robust bearing failure detection is still very challenging since there are many factors influencing the vibration signals from a dynamic bearing system. Furthermore vibration signals generated by train axle bearing are typically nonlinear and non-stationary, making bearing condition detection more difficulty. Features directly related to bearing damages are often hidden in the vibration signals $[27,28]$. In addition, due to the complex nature of the bearing design and operation, it is often difficult to identify the causes of a bearing 
damage $[29,30]$.

This study aims to analyse the effect of bearing damage on bearing vibration by establishing a dynamic model for rail axle bearings. Modeling and simulation methods have become an increasingly accurate approach for predicting the dynamic performance of systems including bearings [31,32]. In modern research and development, $\mathrm{CAE}$ (Computer Aided Engineering) tools have been increasingly used in design and analysis process of mechanical systems. CAE software programs help visualize a system and provide its mechanical properties. Dynamic simulations of rolling bearings increased the understanding of the dynamic behavior and performance of bearings during operation. So all world leading bearing manufacturers have developed their own bearing simulation tools [33-35]. Owing to the high precision on contact geometry description and contact force calculations (including traction), simulations are computationally intensive, and the software of multi-body dynamic has been more and more used in mechanical and bearing dynamic simulation $[36,37]$.

Recently a large number of papers have been published on the detection and diagnosis of bearing defects using dynamic simulation $[38,39]$ but few on the simulation of local damages on rail wheel bearings using mathematical modeling and no investigation has been carried out on the influence of damage size and shape of pits on bearing raceways $[40,41]$.

All types of roller bearings, including tapered roller bearings, spherical roller bearings and cylindrical roller bearings, have been used in rolling stock axles. In this paper, a dynamic model of cylindrical rail axle bearings is developed and the vibration of the damaged bearings is simulated to establish the links between the damage and the vibration. Since damages are often found appear in bearing outer raceways, various surface damage pits on the outer ring is simulated in the dynamic model based on the multi-body dynamic software Recurdyn. In this model, every part of the bearing is modeled three-dimensional according to real rail axle bearing dimensions and various surface damage shape and size on the outer ring are simulated to evaluate the resulted vibration..

\section{Dynamic modeling theory of the rail wheel axle bearing system}

\subsection{Dynamic model of axle bearing}

In order to analysis the vibration characteristics of rail axle bearings, a dynamic model is established including the shaft, wheel, rail, bearing housing, spring and vehicle body (shown in Fig.1). In this dynamic system, the train axle and wheel will rotate and translate together under the power of train, meanwhile the bearing housing and vehicle body, are connected by the suspension springs, will translate. The axle bearings play a key component for transferring the movement and loading between the axle and vehicle, where its outer ring and inner ring move with 
the vehicle and the axle respectively. Based on the movement analysis of this dynamic system, a multiple-degree of freedom model of the axle bearing has been developed, shown in Fig.2, to determine the vibration of the bearing with local damages such as pits during operation. The following assumptions have been made:

1. Without considering the effect of translation of system on vibration, the shaft and bearing inner ring only rotate, and the bearing outer ring, housing and vehicle-body no longer make translation.

2. The quality of axle includes the wheel and other rotating parts connected with the shaft.

3. The rail is assumed to be ground, and the vertical stiffness and damping of the wheel and tail are simplified as $\mathrm{K}_{2}$ and $\mathrm{C}_{2}$.

4. The bearing housing is assumed to be a quality frame.

5. The vertical stiffness and damping of the suspension springs are simplified as $\mathrm{K}_{1}$ and $\mathrm{C}_{1}$, the vehicle body is assumed to be a quality mass, and the loading of vehicle is assumed to be a concentrated force.

6. Deformation in the contact occur of bearings is based upon an extended surface to surface contact force element. The effect of the elastohydrodynamic lubricated (EHL) contact uses the E-CFD solver of RecurDyn.

7. The bearings are assumed to operate under isothermal conditions.

8. The damping in the bearing model is assumed to be lubricating oil damping.

9. The roughness, waviness and roundness effect of bearing raceway are neglected, and the damage pit is also smooth.

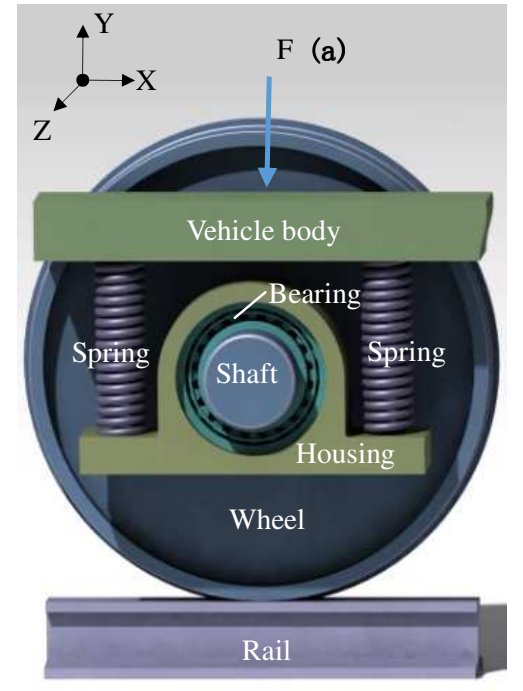

Fig.1. The model of an axel bearing dynamic system

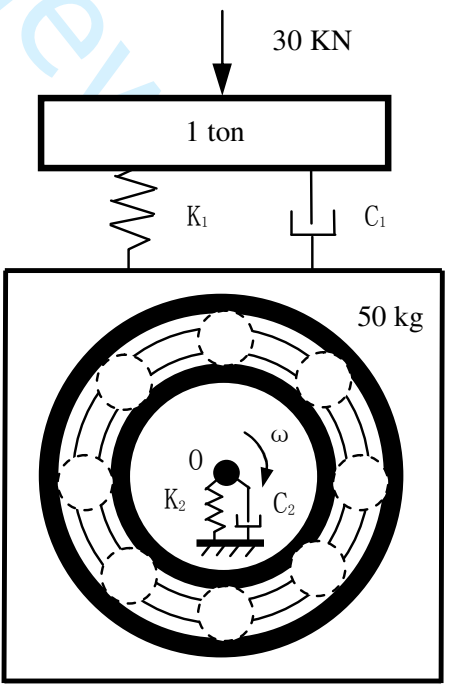

Fig.2. A schematic diagram of the axel bearing dynamic system

\subsection{Geometric model of the bearing and damage pits}


(a)
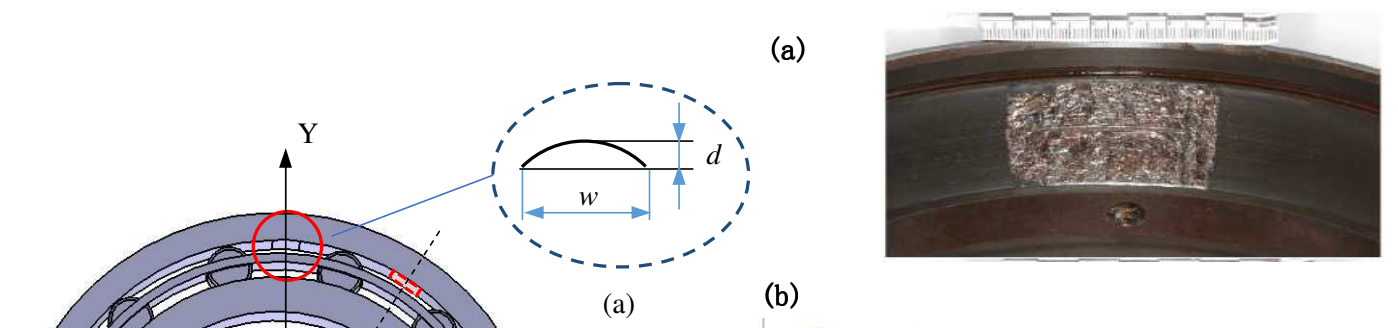

(b)

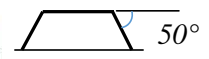

(b)

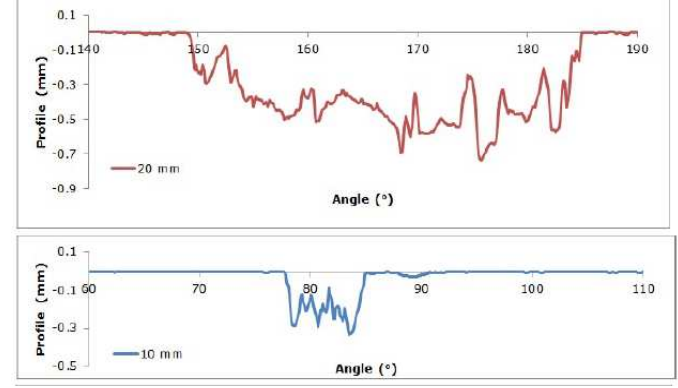

(c)

Fig.4. Figure of damage pit on outer raceway [42]

Fig.3. Model of rail wheel cylindrical roller bearings

In order to study the effect of a damage pit on bearing vibration, a cylindrical roller bearing (F-803419.ZL) with the specifications listed in Table 1 is selected. The inner ring has double ribs while the outer ring does not have a rib and is stationary. A pitting damage on the outer ring has been studied in three shapes based on actual damages found in rail axle bearings [42]: circle, trapezia and step as illustrated in Fig.3.

Table 1: specifications of the cylindrical roller bearings used for the model shown in Fig.3

\begin{tabular}{ll}
\hline Parameters & Values \\
\hline Outer diameter of bearing, Dy & $220 \mathrm{~mm}$ \\
Inner diameter of bearing, dn & $130 \mathrm{~mm}$ \\
Width of bearing, B & $80 \mathrm{~mm}$ \\
Length of roller, Lw & $41.2 \mathrm{~mm}$ \\
Diameter of roller, Dw & $17.8 \mathrm{~mm}$ \\
The number of rollers & 12 \\
\hline
\end{tabular}

The depth of the has been varied between 0.1 and $0.5 \mathrm{~mm}$. the width between 1 and $25 \mathrm{~mm}$ and the angle between bottom face with side face of the pit at about $50^{\circ}$ as found in damaged rail bearings. Since the outer ring is stationary, the position of the pit is thus very important depending on the loading conditions. Bearing damages generally initiate in the loading zone, e.g. the middle of the loading zone at the top of the outer ring in this study. At the pit, rollers will rotate as well as move in and out of the pit. Since the roundness and waviness of surface are typically far less than the size of the damage pit, the effect of surface roughness and waviness on dynamic simulation is not considered in this study.

\subsection{Contact calculation}




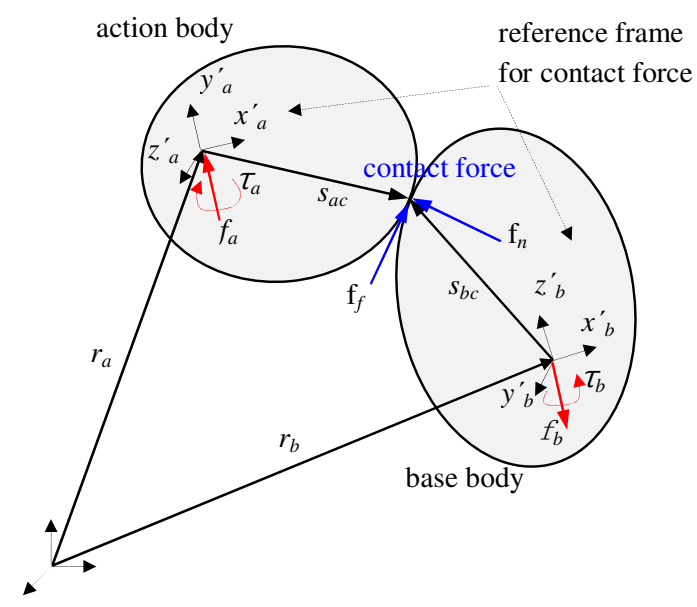

Fig.5. An illustration of the contact forces

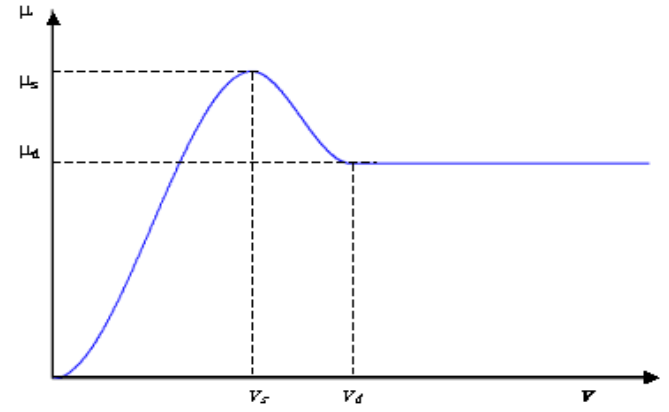

Fig.6. Friction coefficients vs. velocity

The contact forces at the bearing roller-raceway contact are illustrated in Fig. 5, showing the relevant parameters used in calculating the forces. To this dynamic system, contact calculating affects the accuracy of the results of dynamic simulation directly. The contact parameters include stiffness, damping and friction coefficients.The contact normal force is obtained by [43]

$$
f_{n}=k \delta^{m 1}+c \frac{\dot{\delta}}{|\dot{\delta}|}|\dot{\delta}|^{m 2} \delta^{m 3}
$$

a friction force is determined as follows

$$
\begin{aligned}
& f_{f}=\mu(v) \cdot\left|f_{n}\right| \\
& \mu(v)= \begin{cases}\operatorname{step}\left(v, 0,0, v_{s}, \mu_{s}\right) \cdot \operatorname{sign}(-v) & |v|<v_{s} \\
\operatorname{step}\left(v, v_{s}, \mu_{s}, v_{d}, \mu_{d}\right) \cdot \operatorname{sign}(-v) & |v| \geq v_{s}\end{cases}
\end{aligned}
$$

By the tangential velocity of $v$, the friction coefficient of $\mu$ is determined as shown in Fig.6. In this paper, only the dynamic threshold coefficient of friction is set according to the results of the previous experimental study [44].

Stiffness and damping coefficients of a bearing system play significant roles in dynamic simulation. In this paper, the stiffness coefficient $k$ depends on the contact geometry between the roller and raceways. According to literature [45], the stiffness coefficients for an inner race-ball contact and an outer race-ball contact can be expressed as follows, respectively. The nonlinear stiffness associated with point contact is

$$
k=\frac{E}{\left(1-\frac{1}{M^{2}}\right)} \sqrt{\frac{3 r \theta_{i}}{\left(1.5 \frac{2 k}{\Lambda \lambda}\right)^{3} \sum \rho}}
$$

The damping in the rolling contacts include viscous lubricant film damping, frictional damping and material damping. Lubricant film damping is found to be negligible in moderate to high loaded bearings (elastohydrodynamic lubrication condition) [46,47]. Kumer [48] has provided an estimation of the bearing damping, where the rolling element-race vibratory system is reduced to a linear spring-mass damper system. The frequency at which the amplitude 
of the damping force equals to the spring force when a harmonic motion happens, is evaluated based on the following:

$$
C_{m a t}=\frac{\psi}{2 \pi f} K_{B}
$$

\section{Simulation and calculation method}

\subsection{Initial condition}

Based on the model presented above, the vibration response of a bearing with different damage pit during running-in is simulated. The geometry of bearing is shown in Fig. 3(a) with the parameters given in Table 1. The outer ring is assumed to be closely fitted into a frame, which represents the housing of the bearing and the frame is connected to vehicle body through springs. The mass of the frame and vehicle body is $50 \mathrm{~kg}$ and $1000 \mathrm{~kg}$ respectively. The stiffness of the connecting spring is $k_{1}=10^{7} \mathrm{~N} / \mathrm{m}$, and the damping of the suspension is $\mathrm{C}_{1}=10^{5}$ $\mathrm{NS} / \mathrm{m}$. A simple spring support structure has been chosen to represent the wheel and rails. The spring of the wheel and rails is $\mathrm{k}_{2}=10^{9} \mathrm{~N} / \mathrm{m}$, and the damping of the suspension is $\mathrm{C}_{2}=10^{8} \mathrm{NS} / \mathrm{m}$. The load from the vehicle is assumed to be the gravitational load and concentrated force is $30 \mathrm{KN}$. With the presented model, the vibration simulation of axle bearing is simulated during the shaft rotating. The rotational speed of the shaft $\omega$ increases linearly up to 94.2 $\mathrm{rad} / \mathrm{s}$ within $0.02 \mathrm{~s}$. The vibration signals will be processed in both frequency and time-frequency domains. The first eigenfrequency is at $\mathrm{f}=1080 \mathrm{~Hz}$, and the time step in the presented simulation is time $=1 \mathrm{~s}$. Details of the damage pits are given in Section 2. In this section, the circular damage pit at the depth of $0.3 \mathrm{~mm}$ and width of 10 $\mathrm{mm}$ is modeled.

\subsection{Analysis of the vibration signals in time and frequency domains}

The dynamic characteristic of all bearing parts has been obtained by dynamic simulation. The vibration acceleration responses of a damaged and good bearing are shown in the Fig.7. The results have been compared with other researcher's experiments in the literature, where the vibration acceleration of damaged bearing was found to be higher than the measured values due to the rigid model and the lower number of rollers in the simulation [49].

From Fig.7, it can be seen that the acceleration amplitude of damaged bearing is higher than that of the good bearing. In order to analyze the effect of the pit size on the bearing vibration, the acceleration amplitude changing trend is obtained under different depth of pit, see results in Fig.8. It can be seen that, although overall the amplitude increases with the pit depth, the change is not significant especially when the depth is less than $0.3 \mathrm{~mm}$. 


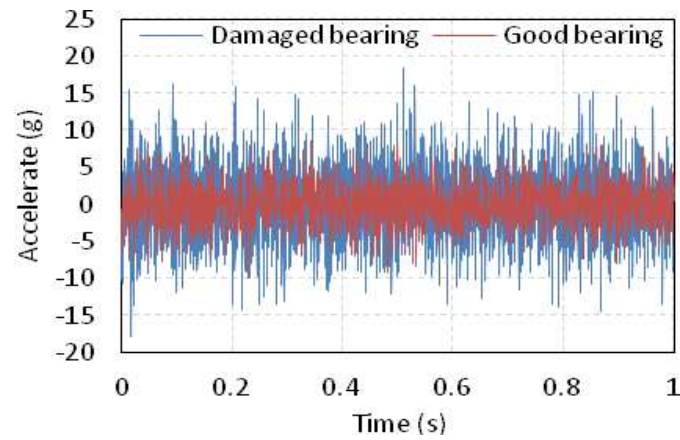

Fig.7. vibration accelerate curves of outer ring

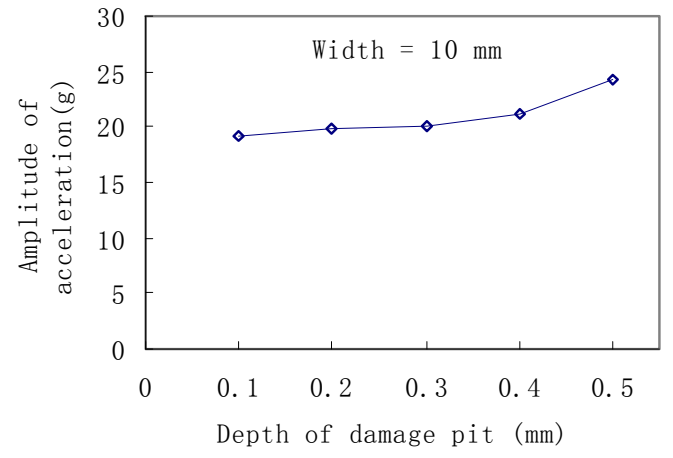

Fig.8. the amplitude of vibration curves

The fundamenttal fault frequencies(in $\mathrm{Hz}$ ) can be calculated using Equation (6):

$$
\left\{\begin{array}{l}
B P F O=\frac{N f_{s}}{2}\left(1-\frac{D_{\omega}}{P} \cos \theta\right) \\
B P F I=\frac{N f_{s}}{2}\left(1+\frac{D_{\omega}}{P} \cos \theta\right) \\
F T F=\frac{f_{s}}{2}\left(1-\frac{D_{\omega}}{P} \cos \theta\right) \\
B S F=\frac{P f_{s}}{2 D_{\omega}}\left[1-\left(\frac{D_{\omega}}{P} \cos \theta\right)^{2}\right]
\end{array}\right.
$$

The bearing's characteristic defect frequencies are shown Table 2. The frequency domain analysis results are shown in Fig. 9. For a normal bearing undergoing steady-state rotation, the response frequencies that may affect bearing life is in the low-frequency range and are usually at single fundamental frequency and double fundamental frequency. Comparing the frequencies from the damaged with the good bearing, the BPFO (at $82 \mathrm{~Hz}$ ) and $2 * \mathrm{BPFO}$ (at $165 \mathrm{~Hz}$ ) are clearly shown in the bearing with a pit in the outer ring.

table2: Bearing parameters and Fundamental Frequencies

\begin{tabular}{|c|c|c|c|c|c|c|c|}
\hline \multicolumn{4}{|c|}{ Bearing Parameters } & \multicolumn{4}{|c|}{ Fundamental Frequencies } \\
\hline $\mathrm{N}$ & fs & Dw & $\mathrm{P}$ & BPFI & BPFO & FTF & BSF \\
\hline 12 & 15 & 17.8 & 170 & 99.4 & 80.6 & 6.7 & 70.8 \\
\hline
\end{tabular}

Further analysis has been conducted to investigate the influence of pit width on all the bearing defect frequencies. Table 3 summarises the results when the depth of the pit was kept at $0.3 \mathrm{~mm}$ when the width was varied from $5 \mathrm{~mm}$ to $20 \mathrm{~mm}$. It can be seen that the BPFI and BPFO and their harmonics appeared in most of the cases. Hence the acceleration at these frequencies can be used to characterize the influence of the pit size. 


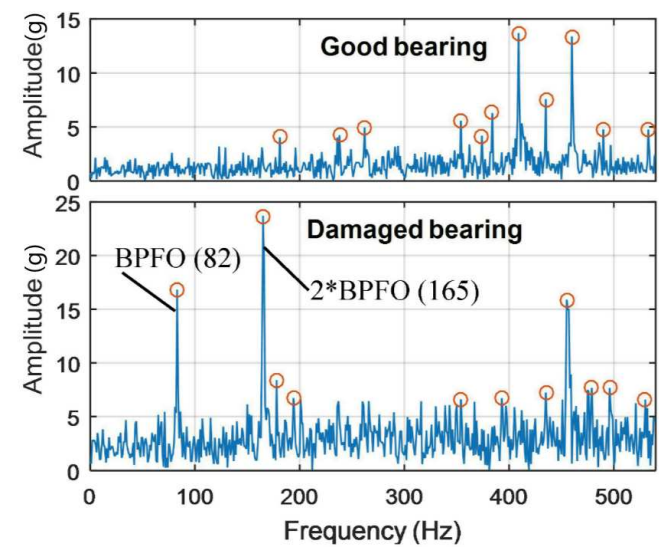

Fig.9. spectrum of outer ring vibration

Table 3: the amplitude of the main frequencies

\begin{tabular}{ccccccccc}
\hline & \multicolumn{2}{l}{$=5 \mathrm{~mm} / \mathrm{d}=0.3 \mathrm{~mm}$} & \multicolumn{2}{c}{$\mathrm{W}=10 \mathrm{~mm} / \mathrm{d}=0.3 \mathrm{~mm}$} & $\mathrm{~W}=15 \mathrm{~mm} / \mathrm{d}=0.3 \mathrm{~mm}$ & \multicolumn{2}{c}{$\mathrm{W=20} \mathrm{mm} / \mathrm{d}=0.3 \mathrm{~mm}$} \\
& Frequency & amplitude & Frequency & amplitude & Frequency & amplitude & Frequency & amplitude \\
\hline BSF & - & - & 70 & 5.224549 & - & - & - & - \\
BPFO & 81 & 5.399347 & 82 & 8.58538 & 83 & 15.58256 & 82 & 19.66778 \\
BPFI & - & - & 99 & 6.266902 & 100 & 5.896482 & 98 & 5.632049 \\
$2 *$ BSF & - & - & - & - & - & - & - & - \\
$2 *$ BPFO & 162 & 13.09461 & 165 & 24.08038 & 166 & 21.24954 & 164 & 16.21499 \\
$2 *$ BPFI & 203 & 6.307496 & 195 & 9.389866 & 194 & 6.504964 & 210 & 6.91522 \\
$3 *$ BPFO & 243 & 7.0563 & 247 & 9.703309 & 242 & 8.771362 & 246 & 8.931934 \\
$4 *$ BPFO & 323 & 6.783241 & 323 & 9.103796 & 322 & 6.375335 & 328 & 6.751706 \\
\hline
\end{tabular}

\subsection{Simulation accuracy analysis}

For the numerical technique, the step size and computing time are important parameters to achieve a good and computationally efficient solution. Especially for nonlinear systems and frequency calculation, different computing time may lead to a totally different statistical data and hence different frequency domain solutions. The larger the computing step, the faster the computation time however the lower resolution can be obtained. On the other hand, a smaller step will lead to a longer computing time. Therefore, the computing step and time should be balanced to achieve an adequate accuracy.

During the following simulation, the eigenfrequency has been set at $\mathrm{f}=540,1080,2160,4320$ and $8640 \mathrm{~Hz}$, and the computing step at $0.5,1,2$ and $3 \mathrm{~s}$.

To investigate the accuracy of the simulation, the vibration displacements from the bearing with a circular pit (its width is $10 \mathrm{~mm}$ and its depth is $0.3 \mathrm{~mm}$ ) on its outer ring obtained using different steps are plotted in Fig.10. There are two kinds of displacement curve which the eigenfrequency is at $\mathrm{f}=1080$ and $8640 \mathrm{~Hz}$. We couldn't find whether the simulation precision has been improved when the eigenfrequency was increased. In order to find out the effect of the eigenfrequency on displacement simulation precision, we can observe local details of vibration displacement 
1

2

3

4

5

6

7

8

9

curves (shown in the Fig.11). Although the overall responses are very similar, the differences can be observed when looking into the details (see responses between 0.2 and $0.205 \mathrm{~s}$ in Fig. 10). It can be seen that, the higher the eigenfrequency the more accurate the simulation was obtained. However to reduce the computation time, the eigenfrequency of $1080 \mathrm{~Hz}$, which is the lowest with sufficient accuracy, has been chosen for further analysis. Similarly, the $1080 \mathrm{~Hz}$ has been selected for the vibration acceleration analysis, see results shown in Fig.12. Hence the minimum step size has been found to $1080 \mathrm{~Hz}$.

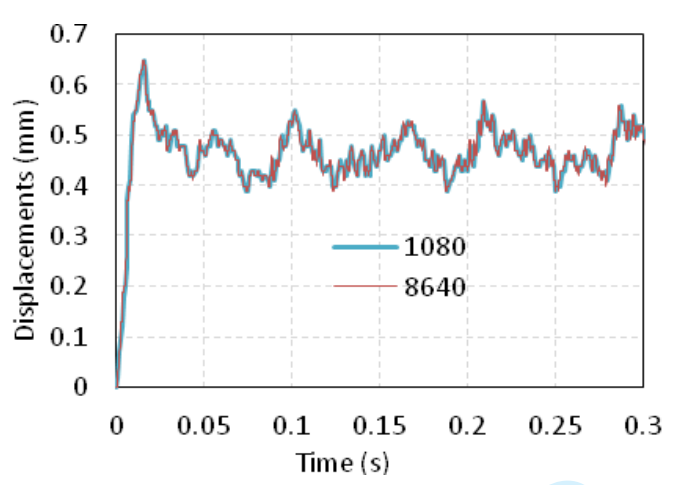

Fig.10. Vibration displacement

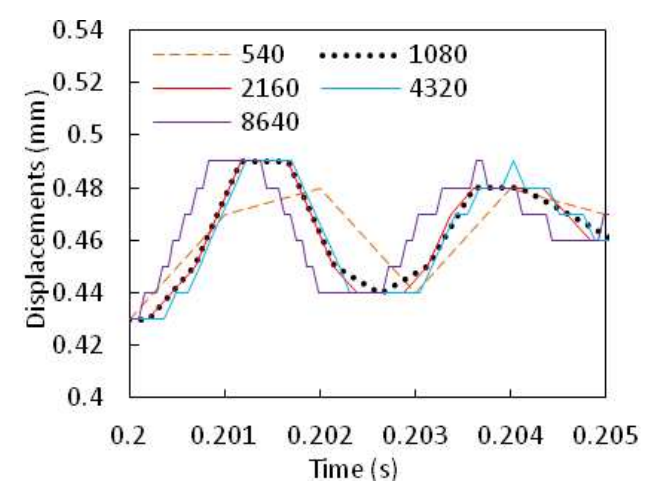

Fig.11. The vibration displacement between 0.2 and 0.205 1080 ------ 2160

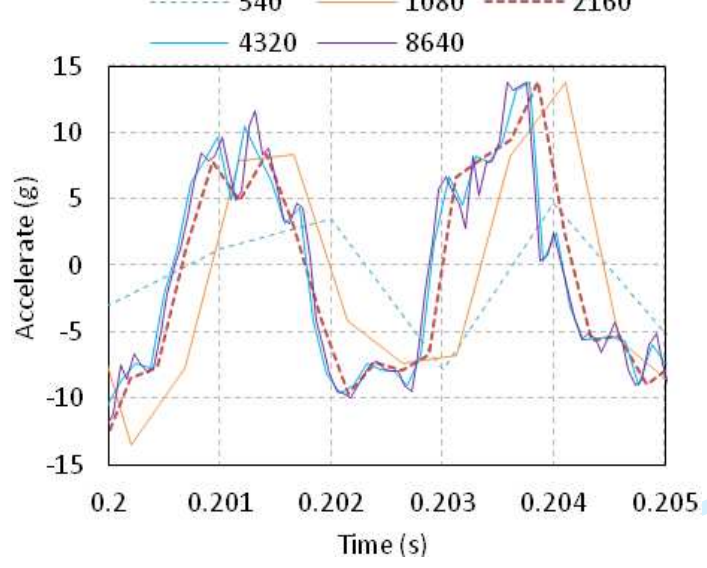

Fig.12. Local details of vibration accelerate curves

In frequency domain analysis, the simulation accuracy may also be affected by simulation time. Since the BPFO and $2 * \mathrm{BPFO}$ are important in identifying the vibration of rail wheel cylinder roller bearings with pit damages in their outer ring, the change of the BPFO and $2 * \mathrm{BPFO}$ with the change of time step and simulation time have been investigated and the results are shown in Figs.13 and 14. It can be seen that the amplitude of BPFO and $2 * B P F O$ becomes stable after the computation step was over $1080 \mathrm{~Hz}$ and when the computation time was over 1s. For further simulations, the eigenfrequency is thus set at $\mathrm{f}=1080 \mathrm{~Hz}$, and the computing time step is set at $1 \mathrm{~s}$. 

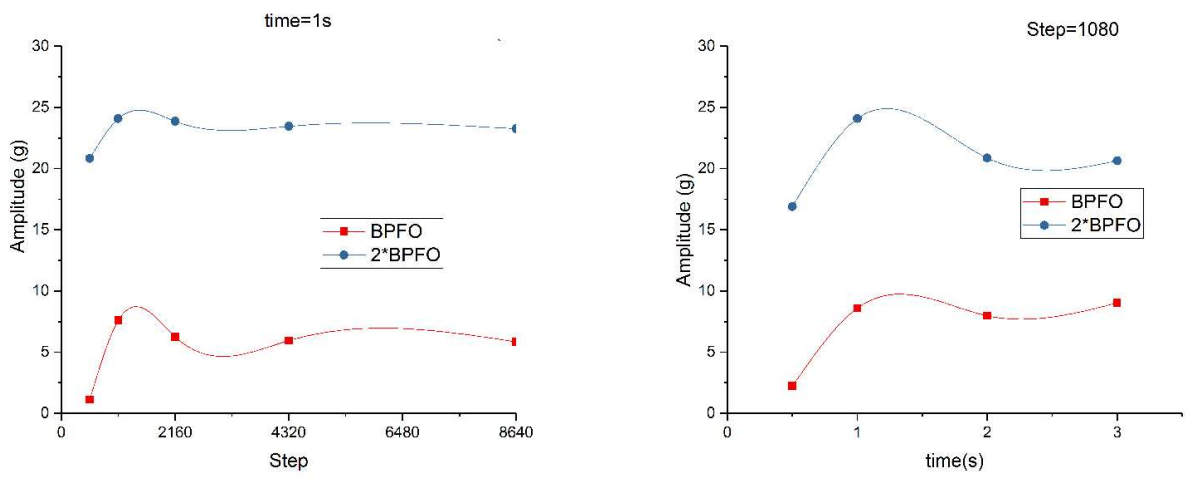

Fig.13. Amplitude of BPFO and $2 *$ BPFO vs. step size Fig.14. Vibration amplitude of BPFO and $2 *$ BPFO vs. computing time

\section{Results and discussions}

\subsection{The location of damage pit on the outer ring}

To study the influence of the pit location on the frequency domain parameters, the vibration responses at various pit position have been simulated. The position of the pit is defined by the angle between the pit and the top centre of the outer ring. Fig. 15 shows the vibration amplitude at the BPFO vs. the angle of a pit on the outer ring. All three types of pits at the depth of $0.3 \mathrm{~mm}$ and width of $10 \mathrm{~mm}$ have been simulated.

As shown in Fig. 15, the BPFO amplitude decreases as the pits from the top centre of the outer ring towards a larger angel with larger differences between the three shapes. The Step shape has the highest amplitude followed by the Trpezia then circular pit. This difference becomes smaller as the angle increases. At 60 degrees, all three shaped pits have similar BPFO amplitude while the amplitude has also reduced to very low. This can be explained that, as the position angle of the pit increases, the load on the roller and the ring reduces gradually, and its effect on the vibration becomes smaller.

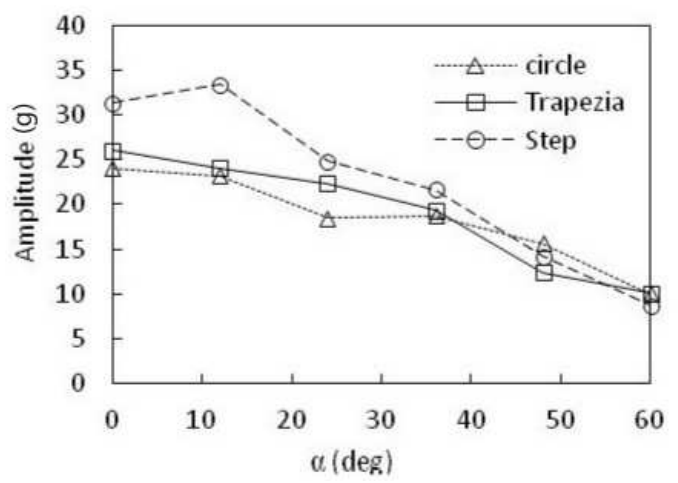

Fig.15. Vibration amplitude vs. pit location

\subsection{Influence of pit shape and size}

Apart from the position of the pit, the influence of the pit shape and size on the vibration is also investigated.

Figs. 16 - 18 present the vibration amplitude vs. pit width for the three pit shapes at both BPFO and $2 \times$ BPFO 
frequencies. For each pit shape, results for three different pit depths have been presented.

For all three pit shapes at BPFO, the vibration amplitude increases with the depth of the pit across the pit width range. However the amplitude at $2 * \mathrm{BPFO}$ has more complicated responses without a universal trend.

The influence of pit width at BPFO also shows an increasing trend as the pit width increases while $2 * \mathrm{BPFO}$ there seems to have a peak vibration at about $10 \mathrm{~mm}$ pit width for all three pit shapes at all three depths investigated and the effect of the pit width on the $2 *$ BPFO amplitude diminishes as the width increases to over $20 \mathrm{~mm}$.

Comparing the vibration responses from different pit shapes, the trends of amplitude changing with pit depth and width at both $\mathrm{BPFO}$ and $2 * \mathrm{BPFO}$ for the circular pits is similar to that for the step shaped pits, while different trends are shown for the trapezia pits. For example, the vibration amplitude at BPFO increases gradually with the pit width for the circular and step pits while it starts and continues at similar level till $20 \mathrm{~mm}$ wide then a sharp increase occurs when the pit width increases from 20 to $30 \mathrm{~mm}$ for the trapezia pits. At $2 * \mathrm{BPFO}$, the vibration amplitude for all three shapes increases initially and reaches a peak value at $10 \mathrm{~mm}$ pit width then starts decreasing, which is different from the vibration at BPFO. These features could be useful in determine the shape and size of a pit on the bearing outer ring based their vibration responses.

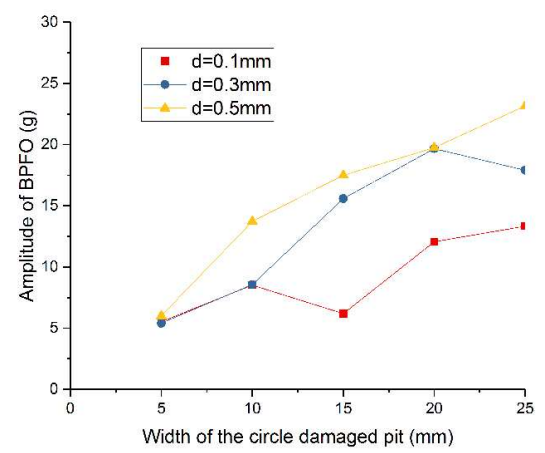

(a)BPFO

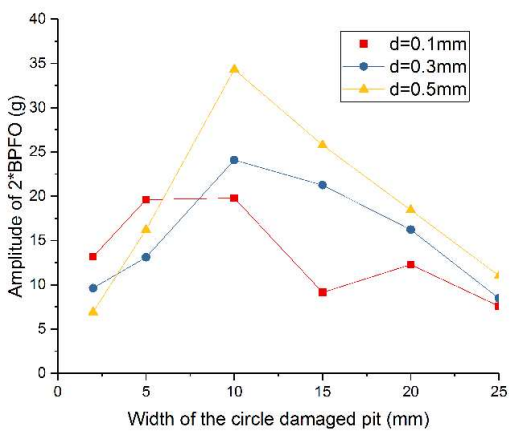

(b) $2 \times \mathrm{BPFO}$

Fig.16. Vibration amplitude vs. pit size for circle pits 


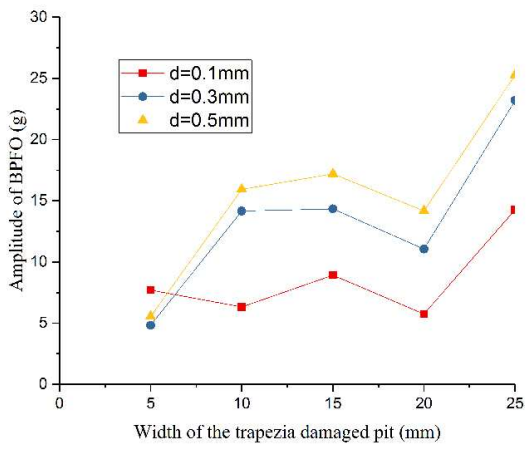

(a)BPFO

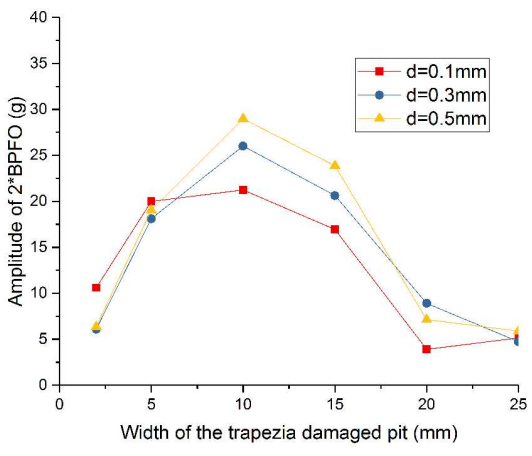

(b) $2 \times \mathrm{BPFO}$

Fig.17. Vibration amplitude vs. pit size for trapezia pits

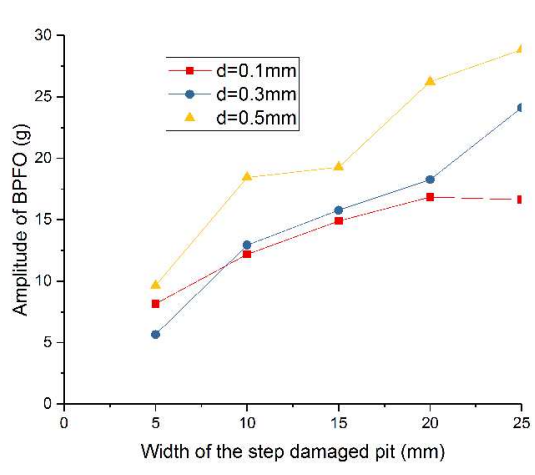

(a)BPFO

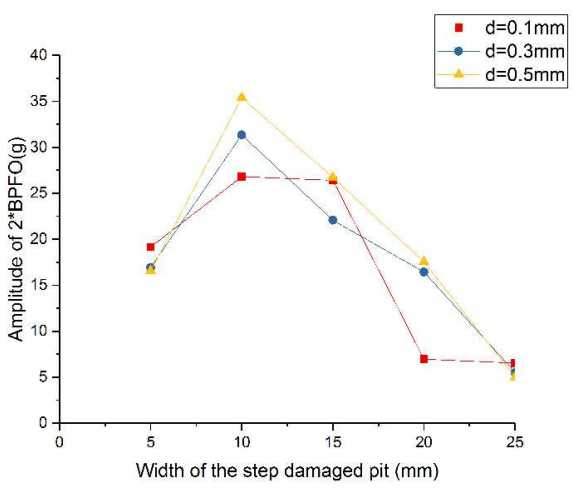

(b) $2 \times$ BPFO

Fig.18. Vibration amplitude vs. pit size for step shape pits

\subsection{Displacement analysis of different damage pits}

To further analyse the effect of different pits on the vibration of rail wheel bearing, the process of roller passing the damage pit is studied by analysing the displacement of the vibration responses. A step size of $8640 \mathrm{~Hz}$ is used in the simulation for two bearing rotation revolutions with a pit of $0.3 \mathrm{~mm}$ depth and $10 \& 15 \mathrm{~mm}$ width on the outer ring (the pit location angle $\alpha=0$ ). Since there are 12 rollers in the bearing, each revolution of bearing rotation will produce 12 wave motions in vibration displacement curves of outer ring as shown in Fig. 10. Fig.19 compares the vibration displacement of the four bearings over 60 degress of rotating angles. Comparing with the bearings with a pit, the good bearing shows a relatively small outer ring displacement with minimum waviness due to change of contact force between the rollers and rings mainly. For all three damaged bearings, there is a sharp increase of displacement during the period when the roller rolls into the damage pit, however the effect of the pit shape on the displacement of outer ring is found to be samilar during this stage (up to 10 degrees) although it continues to increase for longer from step to circular then trapezia pits. The outer ring displacement then reduces before a second peak appears between 40 and 50 degrees where the trapezia pit generates much bigger displacement than that of the step and circular pit. (As the width of circle and step damage pit increasing)If the width of circle and step 
damage pit becomes bigger, the roller will still roll in and out of the pit gradually, and there is no obvious effect for the displacement of the outer ring. But for the trapezia damage pit, the time of roller rolling in the bottom of pit will affect the process of its climbling out of the pit and the secondary fluctuation in this stage. This is the reason why the changing trends of $\mathrm{BPFO}$ and $2 * \mathrm{BPFO}$ of trapezia damage pit are different from the circle and step damage pit.

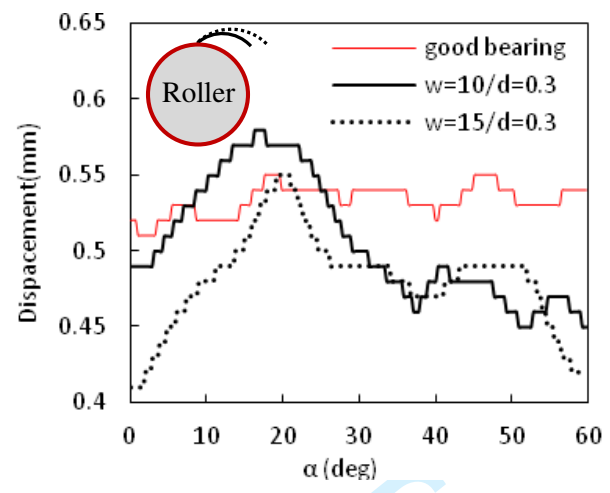

(a) Circle pit

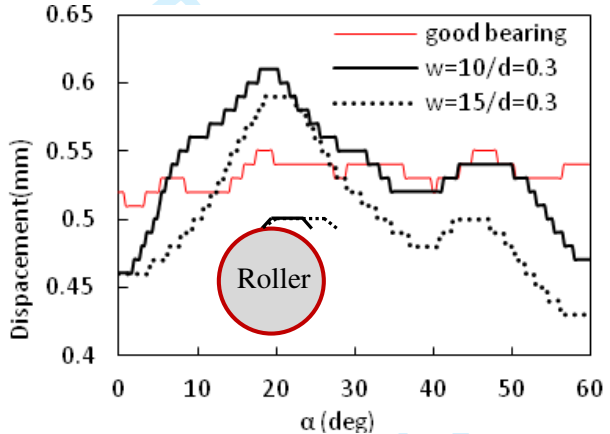

(c) Trapezia pit

Fig.19. Vibration displacement curves vs. angle of rotation

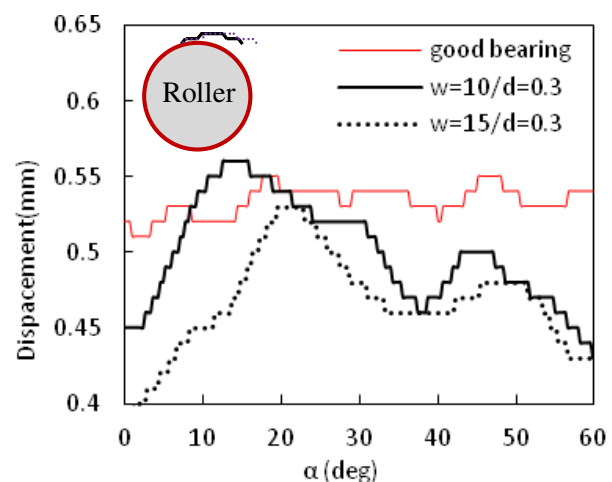

(b) Step pit

\section{Conclusions}

In this paper the effect of damage pits on the time domain and frequency domain of the rail wheel axle bearings dynamic system has been investigated using a multi-body dynamic model. The acceleration responses of the bearing outer ring are compared with those obtained by other researcher's. It was investigated that the vibration acceleration of damage bearing is slightly different from measurement values as the rigid model and number of rollers in the simulation bearings. The model established in this study is evaluated using the frequency components obtained from a mathematical model and those shown in the frequency spectrum of different simulation step and time.

The time and frequency domain analysis of different pit sizes on a bearing outer ring indicates that the damage pits influence the bearing vibration depending on the pit size and shape. The results show, although the pit size (within the range of evaluation) has little influence on the amplitude of the bearing vibration acceleration, it has 
strong influences on the acceleration amplitude at both BPFO and $2 * \mathrm{BPFO}$ of the axle bearing. The main conclusions are:

- The peak value of BPFO decreased when the location of pit is far away from the loading central gradually. And there is obvious difference for different damage pit, which the value of step damage pit is biggest and the value of circle pit is the smallest. When the position angle of pit on the outer ring is greater than $30^{\circ}$, there is little difference among these damage pits and their value intertwined together.

- The peak value of BPFO and $2 * B P F O$ increased when the depth of pits became bigger in general. However, there was no regular rule when the width of pits is smaller than $5 \mathrm{~mm}$. The peak value of BPFO increased when the width of pits became wider. Then the peak value of $2 * \mathrm{BPFO}$ increased when the width from 2 to 10 $\mathrm{mm}$, but they would decrease when the width from 10 to $25 \mathrm{~mm}$. we can determine whether the shape of damage pit belongs to the type of trapezia from the changing trends of BPFO and $2 * \mathrm{BPFO}$. And we can also determine the size of damage pit from the value of BPFO and $2 *$ BPFO. It is helpful for accurate predicting the damaged extent of bearing.

- There were sharp changes of displacement in three kinds of damage bearing when the roller rolled into the damage pit, and the effect of pits shape on the displacement of outer ring are same in this stage. But at the stage of the roller running out of the pits, they showed the different form of climbing out of the pit. There was an obvious secondary fluctuatuon in this stage because of the trapezia damage pit. So it can explain that there are different effects of the damage pits width on the peak value between BPFO and $2 *$ BPFO.

\section{Acknowledgment}

The authors are grateful for the financial support provided by the National Natural Science Foundation of China (No.U1404517) and Integrated Standardization and New Mode Application Project of Intelligent Manufacturing (No.2017ZNZX04).

\section{References}

[1] Kilian MR. Rolling Bearings in High Speed Passenger Traffic. 2010 Joint Rail Conference. 2010, p. 47-56.

[2] Gohar R. Elastohydrodynamics. Imperial College Press, London, 2001

[3] Gohar R and Rahnejat H. Fundamentals of Tribology. Imperial College Press, London, 2008

[4] Sadeghi F. Elastohydrodynamic lubrication. Tribology \& Dynamics of Engine \& Powertrain. 2010; 28: $171-221$.

[5] Johns-Rahnejat, P.M. and Gohar, R., "Point contact elastohydrodynamic pressure distribution and sub-surface stress field” , In Tri-annual conference on multi-body dynamics: monitoring and simulation techniques, Bradford, UK, 1997 
[6] Amini A, Entezami M and Papaelias M. Onboard detection of railway axle bearing defects using envelope analysis of high frequency acoustic emission signals. Case Studies in Nondestructive Testing \& Evaluation. 2016; 6: 8-16.

[7] Broadbridge P and Wake G. A comparison of bearing life in new and refurbished railway axle boxes. 2001.

[8] Papaelias M, Amini A, Huang Z, Vallely P, Dias DC and Kerkyras S. Online condition monitoring of rolling stock wheels and axle bearings. Proceedings of the Institution of Mechanical Engineers Part F Journal of Rail \& Rapid Transit. 2016; 230.

[9] Papaelias M, Huang Z, Amini A, et al. Advanced wayside condition monitoring of rolling stock wheelsets. European Conference on Non-Destructive Testing. 2014.

[10] Vale C, Bonifácio C, Seabra J, et al. Novel Efficient Technologies in Europe for Axle Bearing Condition Monitoring - the MAXBE Project. Transportation Research Procedia. 2016; 14: 635-644.

[11] Vasić G, Ulianov C, Defossez F and Palese JW. Investigation and Guidelines on Use of Monitoring Technologies for Preventing and Reducing the Occurrence of Freight Train Derailments. 2013.

[12] Patel UA and Naik BS. Nonlinear vibration prediction of cylindrical roller bearing rotor system modeling for localized defect at inner race with finite element approach. Proceedings of the Institution of Mechanical Engineers Part $K$ Journal of Multi-body Dynamics. 2016; 231: 647-657.

[13] Wang F, Jing M, Yi J, Dong G, Liu H and Ji B. Dynamic modelling for vibration analysis of a cylindrical roller bearing due to localized defects on raceways. PROCEEDINGS OF THE INSTITUTION OF MECHANICAL ENGINEERS PART KJOURNAL OF MULTI-BODY DYNAMICS. 2015; 229: 39-64.

[14] Salvador P, Naranjo V, Insa R and Teixeira P. Axlebox accelerations: Their acquisition and time-frequency characterisation for railway track monitoring purposes. Measurement. 2016; 82: 301-312.

[15] Elasha F, Mba D, Greaves M and Addali A. Application of Acoustic Emission in Diagnostic of Bearing Faults within a Helicopter Gearbox. International Conference on Through-Life Engineering Services. 2015, p. 30-36.

[16] Vafaei S, Rahnejat $\mathrm{H}$ and Aini R. Vibration monitoring of high speed spindles using spectral analysis techniques. International Journal of Machine Tools \& Manufacture. 2002; 42: 1223-1234.

[17] Lynagh N, Rahnejat $H$, Ebrahimi M and Aini R. Bearing induced vibration in precision high speed routing spindles. International Journal of Machine Tools \& Manufacture. 2000; 40: 561-577.

[18] Liu J, Shao Y and Lim TC. Vibration analysis of ball bearings with a localized defect applying piecewise response function. Mechanism \& Machine Theory. 2012; 56: 156-169.

[19] Patil MS, Mathew J, Rajendrakumar PK and Desai S. A theoretical model to predict the effect of localized defect on 
vibrations associated with ball bearing. International Journal of Mechanical Sciences. 2010; 52: 1193-201.

[20] Graney BP and Starry K. Rolling Element Bearing Analysis. Materials Evaluation. 2012; 70: 78-85.

[21] S. J. Lacey, An Overview of Bearing Vibration Analysis, maintenance \& asset management.2008; 23: 32-42.

[22] Patel VN, Tandon N and Pandey RK. Vibration Studies of Dynamically Loaded Deep Groove Ball Bearings in Presence of Local Defects on Races. Procedia Engineering. 2013; 64: 1582-1591.

[23] Kıral Z and Karagülle H. Vibration analysis of rolling element bearings with various defects under the action of an unbalanced force. Mechanical Systems \& Signal Processing. 2006; 20: 1967-1991.

[24] Cao H, Fan F, Zhou K and He Z. Wheel-bearing Fault Diagnosis of Trains using Empirical Wavelet Transform. Measurement. 2016; 82: 439-449.

[25] Wang C, Jia LM and Li XF. Fault Diagnosis Method for the Train Axle Box Bearing Based on KPCA and GA-SVM. Applied Mechanics \& Materials. 2014; 441: 376-379.

[26] Yi C, Lin J, Zhang W and Ding J. Faults Diagnostics of Railway Axle Bearings Based on IMF's Confidence Index Algorithm for Ensemble EMD. Sensors. 2015; 15: 10991-11011.

[27] Wang X, Zi Y and He Z. Multiwavelet denoising with improved neighboring coefficients for application on rolling bearing fault diagnosis. Mechanical Systems \& Signal Processing. 2011; 25: 285-304.

[28] Ming Y, Chen J and Dong G. Weak fault feature extraction of rolling bearing based on cyclic Wiener filter and envelope spectrum. Mechanical Systems \& Signal Processing. 2011; 25: 1773-1785.

[29] Zhang Y, Zuo $H$ and Bai F. Classification of fault location and performance degradation of a roller bearing. Measurement. 2013; 46: 1178-1189.

[30] Harsha SP and Kankar PK. Stability analysis of a rotor bearing system due to surface waviness and number of balls. International Journal of Mechanical Sciences. 2004; 46: 1057-1081.

[31] Stacke LE and Fritzson D. Dynamic behaviour of rolling bearings: Simulations and experiments. ARCHIVE Proceedings of the Institution of Mechanical Engineers Part J Journal of Engineering Tribology 1994-1996 (vols 208-210). 2001; 215: 499-508.

[32] Gupta PK. Current Status of and Future Innovations in Rolling Bearing Modeling. Tribology Transactions. 2011; 54: 394-403.

[33] Stacke LE, Fritzson D and Nordling P. BEAST - A rolling bearing simulation tool. Proceedings of the Institution of Mechanical Engineers Part K Journal of Multi-body Dynamics. 1999; 213: 63-71.

[34] Houpert L. CAGEDYN: A Contribution to Roller Bearing Dynamic Calculations Part I: Basic Tribology Concepts. 
Tribology Transactions. 2009; 53: 1-9.

[35] S. Mariko, Integrated Bearing Dynamic Analysis System (IBDAS), NTN Technical Review.79(2011)119-124.

[36] Wan Y, Wang S, Le G and Wang F. Performance Analysis on Taper Roller Bearing System Based on Romaxd. International Conference on Modelling, Identification and Control. 2015.

[37] Gummer A and Sauer B. Modeling planar slider-crank mechanisms with clearance joints in RecurDyn. Multibody System Dynamics. 2014; 31: 127-145.

[38] J.Sopanen, A. Mikkola, Dynamic Model of a Deep Groove Ball Bearing Including Localized and Distributed Defects, Part 2: Implementation and Results, J.Multi-body Dynamics. 217(2003)213-223.

[39] Rafsanjani A, Abbasion S, Farshidianfar A and Moeenfard H. Nonlinear dynamic modeling of surface defects in rolling element bearing systems. Journal of Sound \& Vibration. 2009; 319: 1150-1174.

[40] Sawalhi N and Randall RB. Vibration response of spalled rolling element bearings: Observations, simulations and signal processing techniques to track the spall size. Mechanical Systems \& Signal Processing. 2011; 25: 846-870.

[41] Al-Ghamd AM and Mba D. A comparative experimental study on the use of acoustic emission and vibration analysis for bearing defect identification and estimation of defect size. Mechanical Systems \& Signal Processing. 2006; 20: 1537-1571.

[42] Corni I, Symonds N, Wood RJK, Wasenczuk A and Vincent D. Real-time on-board condition monitoring of train axle bearings. The Stephenson Conference - Research for Railways. 2015.

[43] X.J. Jiao, J.W. Zhang, B.B. Peng. Recurdyn Simulation of Multi-body Dynamic system [M]. Beijing: Tsinghua University Press, 2010:179-180.

[44] Wang YS, Deng SE, Yang BY and Yang HS. Investigation on a new five-parameter rheological model of lubricating oil. Tribology. 2007; 27: 461-466.

[45] $\mathrm{He} \mathrm{C}, \mathrm{Xu} \mathrm{H}$ and Zhang Y. Analysis of the nonlinear dynamic response of gyroscope rotor system considered ElastoHydrodynamic Lubrication. International Conference on Mechatronics, Robotics and Automation. 2015.

[46] Dareing DW and Johnson KL. Fluid film damping of rolling contact vibrations. ARCHIVE Journal of Mechanical Engineering Science 1959-1982 (vols 1-23). 1975; 17: 214-218.

[47] Mehdigoli H, Rahnejat $\mathrm{H}$ and Gohar R. Vibration response of wavy surfaced disc in elastohydrodynamic rolling contact. Wear. 1990; 139: 1-15.

[48] B. R. Kumar, S. Ranganatha, A Study of Stiffness and Damping Characteristics of Conventional Fluid and Smart Fluid Applied to Squeeze Film Damper, International Journal of Innovative Technology and Exploring Engineering, IJTEE 
2013, pp.30-34.

[49] Symonds N, Corni I, Wood RJK, Wasenczuk A and Vincent D. Observing early stage rail axle bearing damage. Engineering Failure Analysis. 2015; 56: 216-232. 